\title{
THE APPLICATION OF STRATEGIES COOPERATIVE LEARNING (CL) TO THE HISTORY OF ISLAMIC CULTURE IN THE FORMATION OF STUDENTS' LEARNING CHARACTER AT MADRASAH TSANAWIYAH NEGERI SURAKARTA 1 \\ (Penerapan Strategi Cooperative Learning (Cl) Terhadap Pembelajaran Sejarah Kebudayaan Islam Dalam Pembentukan Karakter Belajar Siswa Madrasah Tsanawiyah Negeri Surakarta 1) \\ Diah Novita Fardani1)
}

1)Institut Agama Islam Negeri Surakarta

*corespondence : diahnovita.novy@gmail.com

\begin{abstract}
Abstrak
This research examines the application of the cooperative learning (CL) model to learning the history of Islamic culture in shaping the character of the students at Madrasah Tsanawiyah Negeri Surakarta 1. This research uses qualitative and descriptive methods. The data collection technique used by the writer was through observation, interview, and documentation techniques as well as the object of research, namely the Cooperative Learning strategy in Islamic Cultural History Learning at Madrasah Tsanawiyah Negeri Surakarta 1 and the research subject was the Islamic cultural history teacher. The application of the cooperative learning (CL) strategy towards learning the history of Islamic culture in shaping the learning character of students at Madrasah Tsanawiyah Negeri Surakarta 1 refers to the type of index card match. In its application, this strategy is carried out properly in accordance with the steps, students become more active in following the learning process. This strategy also plays a very important role in shaping the character of student learning because in its application it is very relevant and responsive in accordance with the times.
\end{abstract}

\section{Abstrak}

Penelitian ini mengkaji tentang penerapan model cooperative learning (CL) terhadap pembelajaran sejarah kebudayan Islam dalam pembentukan karakter siswa Madrasah Tsanawiyah Negeri Surakarta 1. Penelitian ini menggunakan metode kualitatif dan deskriptif. Teknik pengumpulan data yang dilakukan yang digunakan penulis melalui teknik observasi, wawancara, dan dokumentasi serta objek penelitian yaitu strategi pembelajaran Coorperatif Learning di Pembelajaran Sejarah Kebudayaan Islam di Madrasah Tsanawiyah Negeri Surakarta 1 dan subjek penelitian yaitu guru sejarah kebudayaan Islam. Penerapan strategi cooperative learning (CL) terhadap pembelajaran sejarah kebudayaan Islam dalam pembentukan karakter belajar siswa Madrasah Tsanawiyah Negeri Surakarta 1 merujuk pada tipe index card match. Dalam penerapannya strategi ini dilaksanakan dengan baik sesuai dengan langkah-langkah, siswapun menjadi lebih aktif dalam mengikuti proses pembelajaran. Strategi ini juga berperan sangat penting bagi pembentukan karakter belajar siswa karena dalam penerapannya sangat relevan dan responsif sesuai dengan perkembangan zaman.

\section{Article Info}

Article History

Received : 30-01-2021

Revised : 30-01-2021

Accepted : 31-01-2021

Keywords:

Learning; Coorperative

Learning; Learning

Character
Histori Artikel
Diterima : 30-01-2021
Direvisi : 30-01-2021
Disetujui : 31-01-2021

Kata Kunci:

Pembelajaran;

Coorperative Learning;

Karakter Belajar 
Diah Novita Fardani.

\section{A. PENDAHULUAN}

Pendidikan merupakan hal yang penting bagi kebudayaan dan peradaban manusia saat ini. Hal ini sejalan dengan perkembangan zaman yang semakin maju dan canggih. Pendidikan diartikan sebagai salah satu cara untuk memperoleh ilmu dan memperbaiki karakter seseorang, dengan adanya pendidikan dapat memberikan pembelajaran bagi manusia untuk menjadi manusia yang memiliki ilmu pengetahuan dan teknologi serta memiliki Iman dan Taqwa yang kuat, sesuai dengan tujuan pendidikan Nasional.

Interaksi yang harmonis harus dilakukan oleh guru dan siswa dalam proses pembelajaran serta interaksi yang dilakukan harus menghasilkan suatu hubungan timbal balik antara guru dan siswa sehingga dalam proses pembelajaran guru harus dapat mengembangkan potensi yang ada pada diri siswa, apabila guru menghendaki proses pembelajaran berlangsung dengan aktif. Guru perlu menggunakan strategi Cooperative Learning karena strategi ini dapat membuat siswa agar saling membantu dalam mempelajari suatu bahan ajar atau materi sehingga strategi Cooperative Learning tepat digunakan karena merupakan strategi belajar teman sebaya selain itu penerapan strategi Cooperative Learning dalam upaya pembentukan karakter belajar siswa mengharapkan siswa dapat menunjukan sikap kerja sama, jujur, bertanggung jawab, bersemangat dan peduli satu sama lain (Nur, 2018 : 147) yang dapat di wujudkan dalam bentuk belajar siswa seperti siswa aktif saat proses pembelajaran, bersemangat dalam belajar dan bersikap sopan. Maka dari itu, penggunaan strategi pembelajaran Cooperative Learning diharapkan dapat mengembangkan potensi dalam diri siswa kemudian pembelajaran dapat berlangsung dengan harapan dapat membina karakter belajar siswa. Namun, realitanya guru terkadang kurang tepat menerapkan. Hal ini dikarenakan guru hanya terpaku pada materi pelajaran agar dapat tersampaikan kepada siswa.

Berdasarkan permasalahan diatas maka penerapan strategi Cooperative Learning selain digunakan untuk menciptakan suatu pembelajaran yang aktif juga harus dapat membentuk karakter belajar siswa. Sehingga peniliti bermaksud untuk menganalisis penerapan strategi Cooperative Learning terhadap pembelajaran Sejarah Kebudayaan Islam dalam pembentukan karakter belajar siswa Madrasah Tsanawiyah Surakarta Negeri I, dengan mengambil pokok pembahasan terkait penerapan strategi Cooperative Learning dalam pembentukan karakter belajar siswa.

\section{B. METODE PENELITIAN}

Penelitian ini dilaksanakan di Madrasah Tsanawiyah Negeri Surakarta 1, di Jl. MT Haryono, Surakarta, Jawa Tengah. Penulis menggunakan metode kualitatif dan deskriptif sebagai prosedur penelitian yang dapat mengahasilkan 
data deskriptif yang bertujuan mengumpulkan data-data, fakta, berupa tulisan dan perilaku yang diamati pada saat subjek penelitian.

Teknik pengumpulan data yang dilakukan yang digunakan penulis melalui teknik observasi, wawancara, dan dokumentasi. Observasi yang dilakukan penulis dengan secara langsung mengamati terhadap objek penelitian yaitu strategi pembelajaran Cooperative Learning di Pembelajaran Sejarah Kebudayaan Islam di Madrasah Tsanawiyah Negeri Surakarta 1 dan subjek penelitian yaitu guru sejarah kebudayaan Islam selain itu, jenis wawancara yang digunakan yaitu wawancara tidak terstruktur yang mana penulis menanyakan beberapa pertanyaan kepada subjek penleitian yaitu guru mata pelajaran Sejarah Kebudayaan Islam serta teknik dokumentasi yang digunakan untuk mencari informasi terkait dengan penelitian. Sumber data yang di analisis dalam penelitian ini yaitu data primer yang diperoleh langsung dari lapangan melalui pengamatan dan wawancara, kemudian data sekunder yang didapat dari studi pustaka dan literature-literature yang berkaitan dengan penelitian.

\section{PEMBAHASAN}

\section{Pembelajaran Sejarah Kebudayaan Islam}

Sejarah kebudayaan Islam terdiri dari kata yaitu sejarah, kebudayaan dan Islam. Kata sejarah berasal dari kata syajarah yang berarti pohon, Ibnu Khaldun berpendapat bahwa sejarah merupakan catatan umat manusia tentang perubahan watak masyarakatnya. Kemudian, kata kebudayaan berasal dari bahasa sansekerta yaitu buddhayah yang merupakan bentuk jama' buddhi yang berarti daya atau akal. Secara istilah, koentjaraningrat berpendapat bahwa kebudayaan merupakan seluruh sistem gagasan, hasil karya manusia dengan belajar dalam rangka kehidupan manusia menjadi miliknya, sedangkan kebudayaan Islam merupakan suatu budaya yang dibangun dengan landasan Islam sehingga dengan islam kebudayan dapat dinaunginya serta dapat membekali dengan visi historis terhadap diri kulturalnya (Zulfa, 2018 : 56) .

Sejarah Kebudayaan Islam merupakan rumpun mata pelajaran pendidikan agama Islam yang mempelajari mengenai asal-usul, perkembangan peranan kebudayaan dan para tokoh yang berprestasi dalam sejarah Islam di masa lampau, sejak masyarakat Arab Pra Islam hingga masa sekarang maka dari itu melalui mata pelajaran sejarah kebudayaan Islam dapat memberikan motivasi kepada peserta didik untuk dapat mengenal, menghayati sejarah kebudayaan islam yang kemudian dapat dijadikan pegangan hidup melalui pengajaran, keteladana, pembiasaan yang diberikan oleh guru (Maryamah, 2014 : 257). Dengan demikian, dapat disimpulkan bahwa sejarah kebudayaan Islam merupakan mata pelajaran yang 
Diah Novita Fardani.

mempelajari mengenai kebudayaan masa lampau dengan tujuan dapat memberikan motivasi kepada siswa.

2. Pembelajaran Cooperative Learning dalam Pembentukan Karakter Belajar Siswa

a. Pembelajaran Cooperative Learning

Pembelajaran cooperative learning menurut falsafah negara merupakan homo homini socius yang menekankan bahwa manusia adalah makhluk sosial (Suyadi, 2013 : 61). Banyak pendapat mengenai cooperative learning salah satunya menurut Tom V. Savage yang berpendapat bahwa cooperative learning merupakan suatu pendekatan yang menekankan pada kerja sama kelompok (Rusman, 2013 : 203). Jadi, pembelajaran cooperative learning merupakan suatu pembelajaran yang dapat melatih siswa untuk berkerja sama dengan siswa lain dalam kelompoknya demi tercapainya tujuan

Pembelajaran coopetative learning memiliki empat unsur penting di dalamnya yaitu, yaitu adanya peserta didik dalam kelompok, aturan kelompok, upaya belajar setiap anggota kelompok, dan tujuan yang harus dicapai (Suyadi, 2013 : 61). Melalui pembelajaran cooperative learning dapat melatih siswa belajar berpikir kritis karena pembelajaram ini menekankan siswa untuk berkerjasama dengan siswa lain secara sinergis, integral dan kombinatif serta siswa dapat terhindar dari sikap mementingkan diri sendiri (Nur, 2018 : 152). Dalam penerapan pembelajaran cooperative learning pada umumnya siswa bekerja sama dalam suatu kelompok kecil yang terdiri dari 2-6 siswa serta penerapan pembelajaran cooperative learning sangat berguna dalam pembentukan karakter anak, karena selain anak tidak menjadi egois dan individualistis siswa juga dapat bertanggung jawab terhadap tugas yang dikerjakan. (Warsono \& Hariyanto, 2012 : 162)

b. Nilai-Nilai Karakter dalam Cooperative Learning (CL)

Dalam pembelajaran cooperative learning terdapat nilai-nilai karakter didalamnya yakni sebagai berikut :

1. Kepedulian sosial, melalui cooperative learning dapat menjadikan siswa yang pandai menjadi peduli terhadap siswa kurang pandai, karena jika terdapat siswa yang tidak peduli akan berdampak buruk bagi anggota kelompoknya ;

2. Tanggung jawab, nilai tanggung jawab dalam pembelajaran kooperatif (cooperative learning) yakni dalam penyelesaian tugas kelompoknya, karena anggota kelompok memiliki tanggung jawab untuk berbagi kepada siswa lain yang dirasa kurang pandai ; 
3. Toleransi, melalui cooperative learning siswa dapat menghargai perbedaan, karena berangkat dari tingginya toleransi tersebut dapat mendorong siswa untuk untuk bekerja sama dengan anggota kelompoknya ;

4. Kerja keras, dalam kelompok penerpaan pembelajaran kooperatif (cooperative learning) secara alamiah mendorong masing-masing peserta didik untuk bekerja keras dalam mempersembahkan karya terbaik demi kebaikan kelompoknya ;

5. Bersahabat dan Komunikatif, tidak dapat diragukan lagi bahwa strategi pembelajaran kooperatif (cooperative learning) dapat menanamkan nilai-nilai komunikatif dan, peserta didik yang semula kurang akrab terpaksa harus akrab dan menjalin komunikasi intensif dalam suatu kelompok (Suyadi, 2013 : 66-68)

c. Bentuk Strategi Cooperative Learning (CL)

Diantara bentuk model strategi cooperative learning (CL) adalah : index card match. Index card match adalah merupakan suatu untuk mencari pasangan kartu, startegi ini cukup menyenangkan. Index card match lebih cocok digunakan sebagai startegi evaluasi (Rambe, 2018 : 101). Dalam strategi cooperative learning (CL) memiliki kelebihan dan kekurangan, adapun kelebihannya yaitu pembelajaran menjadi lebih menarik karena menggunakan berbagai kartu, model pembelajaran yang dapat meningkatkan kerjasama siswa serta dapat menumbuhkan kreativitas belajar siswa (Marlina, Zulfadli, \& Nazar, 2017 : 138). Namun, kekurangan pada strategi ini yaitu siswa akan kesulitan dalam mencari pasangan jika soalnya dalam bentuk hitungan dan kurang menyesuaikan materi dengan kebutuhan siwa (Marlina, Zulfadli, \& Nazar, 2017 : 138). Prosedur pelaksanaan index card match yakni :

1. Guru menyiapkan peralatan untuk membuat kartu anakan dan kartu indukan

2. Guru membuat kartu anakan sejumlah siswa dalam kelas

3. Guru membagiksn kartu menjadi dua bagian yang sama kepada siswa, separuh siswa mendapatkan kartu yang berisi pertanyaan dan yang sisanya mendapatkan kartu jawaban

4. Setiap siswa yang telah mendapatakn kartu, guru memberikan penjelasan kepada siswa bahwa proses pembelajaran yang dilakukan berpasangan

5. Guru meminta kepada siswa untuk menemukan pasangan mereka. Jika ada yang sudah menemukan pasangan, mintalah kepada mereka untuk duduk berdekatan 
6. Setelah siswa menemukan pasangan, Guru meminta kepada setiap pasangan secara bergantian untuk membacakan soal yang diperoleh dengan keras kepada temannya yang lain. Selanjutnya soal tersebut dijawab oleh pasangannya

7. Setelah pasangan membacakan jawaban, guru memberikan klarifikasi kepada siswa (Rambe, 2018 : 101).

Berdasarkan hasil observasi, wawancara, dan dokumentasi dalam pembelajaran. Dalam observasi yang penulis lakukan di kelas VII Program Keagamaan (PK) 3 di Madrasah Tsanawiyah Negeri 1 Surakarta dengan materi pola dakwah Nabi di Mekkah. Guru pengajar mata pelajaran Sejarah Kebudayaan Islam yaitu Iqbal Setiawan mempersiapkan pelajaran dengan menggunakan perangkat pembelajaran yaitu RPP (Rencana Pelaksanaan Pembelajaran).

Penerapan kurikulum di Madrasah Tsanawiyah Negeri 1 Surakarta menggunakan kurikulum 2013 sehingga dalam penyusuna RPP menggunakan pembelajaran saintifik yang terdiri dari lima langkah yaitu mengamati, menanya, mengeksplorasi, mengasosiasikan dan mengkomunikasikan. Adanya kelima langkah tersebut dalam pembelajaran membuat guru harus menerapkan strategi pembelajaran yang tepat. Dalam hal ini penerapan startegi cooperative learning $(C L)$ terhadap pembelajaran sejarah kebudyaan Islam dalam pembentukan karakter belajar siswa di Madrasah Tsanawiyah Negeri 1 Surakarta merujuk pada strategi cooperative learning model index card match.

Proses pembelajaran di kelas VII PK 3 dengan Bp. Iqbal Setiawan selaku guru SKI tertuang sesuai dengan RPP. Kegiatan awal pada proses pembelajaran atau sering disebut dengan pendahuluan, guru memulai pembelajaran dengan membaca Asmaul Husna dan membaca Al-Qur'an. Setelah itu, guru melakukan absensi dan apersepsi terkait materi yang sudah diajarkan pada pertemuan sebelumnya. Sebelum masuk pada pembelajaran inti, guru memberikan apresiasi sekaligus motivasi kepada siswa, agar siswa lebih bersemangat dalam mengikuti proses pembelajaran.

Kegiatan inti pada proses pembelajaran di kelas VII PK 3 yang di dalamnya memuat langkah-langkah pembelajaran saintifik yaitu :

Tabel 1. Langkah Pembelajaran dengan Nilai Karakter

\begin{tabular}{|l|l|l|}
\hline $\begin{array}{l}\text { Langkah } \\
\text { Pembelajaran }\end{array}$ & Deskripsi Kegiatan & $\begin{array}{l}\text { Nilai Pendidikan } \\
\text { Karakter }\end{array}$ \\
\hline
\end{tabular}




\begin{tabular}{|c|c|c|}
\hline Mengamati & $\begin{array}{l}\text { Pada tahap ini, siswa } \\
\text { mendengarkan penjelasan } \\
\text { dari guru berkaitan dengan } \\
\text { materi pelajaran pola } \\
\text { dakwah Nabi Muhammad } \\
\text { SAW di Mekkah. }\end{array}$ & $\begin{array}{l}\text { Pada tahapan yang } \\
\text { dilakukan guru, } \\
\text { mengandung nilai } \\
\text { pendidikan karakter } \\
\text { yang berupa nilai } \\
\text { tanggungjawab } \\
\text { pada diri siswa. } \\
\text { Karena siswa } \\
\text { bertanggung jawab } \\
\text { pada dirinya sendiri } \\
\text { untuk } \\
\text { mendengarkan } \\
\text { materi yang } \\
\text { disampaikan oleh } \\
\text { guru. }\end{array}$ \\
\hline Menanya & $\begin{array}{l}\text { Pada tahap ini, guru SKI } \\
\text { memberikan kesempatan } \\
\text { kepada siswa untuk } \\
\text { menanyakan hal-hal yang } \\
\text { belum mereka pahami }\end{array}$ & $\begin{array}{l}\text { Pada tahap ini, guru } \\
\text { memancing siswa } \\
\text { untuk bertanya } \\
\text { berkaitan dengan } \\
\text { hal-hal yang belum } \\
\text { dipahami siswa. } \\
\text { Nilai pendidikan } \\
\text { karakter yang } \\
\text { terkandung } \\
\text { didalamnya yaitu } \\
\text { siswa menjadi lebih } \\
\text { komunikatif selain } \\
\text { itu menjadi lebih } \\
\text { berani. }\end{array}$ \\
\hline Mengeksplorasi & $\begin{array}{l}\text { Pada tahap ini, guru SKI } \\
\text { menerapkan strategi } \\
\text { pembelajaran yang berupa } \\
\text { strategi cooperative learning } \\
\text { tipe index card match. } \\
\text { Namun, sebelum penerapan } \\
\text { strategi tersebut siswa } \\
\text { diberi satu lembar kertas } \\
\text { berupa mind mapping dan } \\
\text { siswa diminta untuk } \\
\text { melengkapi dan mengisi }\end{array}$ & $\begin{array}{l}\text { Pada tahapan ini, } \\
\text { guru menerapkan } \\
\text { strategi cooperative } \\
\text { learning tipe index } \\
\text { card match yang } \\
\text { digunakan oleh } \\
\text { guru. Guru } \\
\text { mengharapkan } \\
\text { dengan } \\
\text { diterapkannya } \\
\text { strategi ini siswa }\end{array}$ \\
\hline
\end{tabular}


Diah Novita Fardani.

\begin{tabular}{|c|c|c|}
\hline & $\begin{array}{l}\text { jawaban pada kotak yang } \\
\text { telah disediakan. } \\
\text { Kemudian, setelah selesai } \\
\text { guru menyuruh siswa } \\
\text { untuk menutup buku dan } \\
\text { mulai memberi arahan } \\
\text { bagaimana proses } \\
\text { penerapan strategi } \\
\text { cooperative learning tipe } \\
\text { index card match. Siswapun } \\
\text { sangat antusias dalam } \\
\text { mendengarkan arahan yang } \\
\text { diberikan oleh guru. Setelah } \\
\text { memberikan pengarahan } \\
\text { guru membagikan potongan } \\
\text { kertas yang } \quad \text { berisi } \\
\text { pertanyaan dan jawaban } \\
\text { secara acak kepada siswa. } \\
\text { Guru bermaksud membagi } \\
\text { siswa secara berapasangan } \\
\text { untuk mencocokan antara } \\
\text { kartu pertanyaan dan kartu } \\
\text { jawaban }\end{array}$ & $\begin{array}{l}\text { menjadi lebih aktif } \\
\text { dalam proses } \\
\text { pembelajaran dan } \\
\text { siswa mampu } \\
\text { bekerja sama secara } \\
\text { sinergis, integral, } \\
\text { dan kombinatif. } \\
\text { Sehingga nilai } \\
\text { pendidikan karakter } \\
\text { yang ada pada } \\
\text { proses pembelajaran } \\
\text { dapat membentuk } \\
\text { karakter siswa. }\end{array}$ \\
\hline $\begin{array}{l}\text { Mengasosiasika } \\
\text { n }\end{array}$ & \begin{tabular}{l}
\multicolumn{3}{l}{ Pada saat, guru telah selesai } \\
membagi kartu, guru \\
menyuruh siswa untuk \\
mencari pasangan kartunya. \\
Bagi siswa yang telah \\
menemukan \\
kartunya pasangan \\
diminta untuk membacakan \\
pertanyaan dan jawabannya \\
jika sudah tepat maka \\
selanjutnya guru akan \\
memberikan \\
lebih lanjut kepada siswa
\end{tabular} & 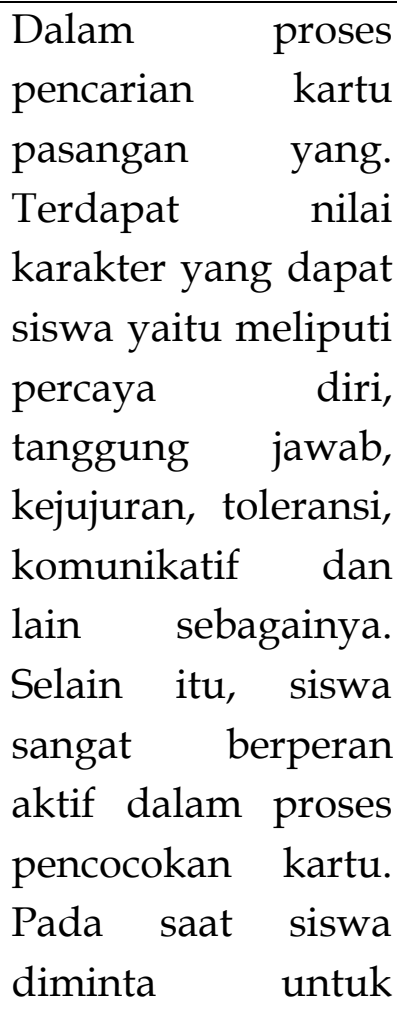 \\
\hline
\end{tabular}




\begin{tabular}{|c|c|c|}
\hline & & $\begin{array}{lr}\text { membacakan } \\
\text { jawaban dan } \\
\text { pertanyaan siswa } \\
\text { bergantian } \\
\text { membacakan serta } \\
\text { dalam membacakan } \\
\text { pasangan kartunya } \\
\text { siswaraga } \\
\text { bertanggung jawab } \\
\text { terhadap } \\
\text { jawabannya. }\end{array}$ \\
\hline $\begin{array}{l}\text { Mengkomunika } \\
\text { sikan }\end{array}$ & $\begin{array}{l}\text { Pada langkah ini, guru } \\
\text { memberikan penjelasan } \\
\text { terhadap jawaban siswa } \\
\text { serta memberikan } \\
\text { pertanyaan untuk melihat } \\
\text { pemahaman siswa }\end{array}$ & $\begin{array}{l}\text { Pada tahap ini, guru } \\
\text { memberikan } \\
\text { penjelasan terhadap } \\
\text { jawaban siswa } \\
\text { supaya siswa dapat } \\
\text { lebih memahami } \\
\text { materi yang telah } \\
\text { diajarkan, namun } \\
\text { dilanjutkan dengan } \\
\text { memberikan } \\
\text { pertanyaan kepada } \\
\text { siswa. Namun, } \\
\text { respon siswa sangat } \\
\text { aktif terbukti siswa } \\
\text { saling berebut } \\
\text { ketika menjawab } \\
\text { pertanyaan yang } \\
\text { diberikan guru. }\end{array}$ \\
\hline
\end{tabular}

Pada kegiatan penutup guru memberikan kesimpulan terkait hasil pembelajaran dan menyampaikan kegiatan pembelajaran pada pertemuan selanjutnya dan diakhiri dengan salam.

Hasil wawancara bersama guru sejarah kebudayaan Islam terkait penerapan strategi cooperative learning (CL) terhadap pembelajaran sejarah kebudayaan Islam dalam pembentukan karakter belajar siswa Madrasah Tsanawiyah Negeri Surakarta 1 menyatakan bahwa melalui strategi ini siswa justru jauh siswa jauh lebih aktif daripada menggunakan strategi yang diterapkan sebelumnya yaitu talking stick. Serta dalam pembentukan karakter belajar siswa melalui penerapan strategi ini siswa menjadi bersemangat dalam 
Diah Novita Fardani.

mengikuti proses pembelajaran sehingga siswa memiliki rasa ingin tahu yang lebih tinggi. Selain itu, juga nilai karakter kejujuran karena pada saat proses pembelajaran siswa dilarang untuk membuka materi yang ada dibuku modul. Kemudian sopan santun dalam mencari pasangan kartu dan mempertanggung jawabkan terhadap pasangan kartu yang telah ditemukan. Jadi, dapat disimpulkan bahwasannya Penerapan strategi cooperative learning (CL) terhadap pembelajaran sejarah kebudayaan Islam dalam pembentukan karakter belajar siswa madrasah tsanawiyah surakarta 1 dapat membentuk karakter belajar siswanya.

\section{SIMPULAN}

Berdasarkan pembahasan di atas dapat ditarik kesimpulan mengenai penerapan strategi cooperative learining (CL) terhadap pembelajaran sejarah kebudayaan Islam dalam pembentukan karakter siswa madrash tsanawiyah surakarta 1 bahwa : Penerapan strategi cooperative learning (CL) terhadap pembelajaran sejarah kebudayaan Islam dalam pembentukan karakter belajar siswa Madrasah Tsanawiyah Surakarta 1 merujuk pada tipe index card match. Dalam penerapannya strategi ini dilaksanakan dengan baik sesuai dengan langkah-langkah, siswapun menjadi lebih aktif dalam mengikuti proses pembelajaran. Strategi ini juga berperan sangat penting bagi pembentukan karakter belajar siswa karena dalam penerapannya sangat relevan dan responsif sesuai dengan perkembangan zaman.

\section{Daftar Rujukan}

Marlina, Zulfadli, \& Nazar, M. (2017). Penerapan Model Pembelajaran Index Card Match pada Materi Hukum-hukum Dasar Kimia di Kelas X SMA Inshafuddin Banda Aceh. Jurnal Ilmiah Mahasiswa Pendidikan Kimia (JIMPK), Vol.2. No.3.

Maryamah. (2014). Teknik Mind Mapping dan Hasil Belajar Siswa pada Pembelajaran Sejarah Kebudayaan Islam di Madrasah Ibtidaiyah Adabiyah II Palembang. Ta'dib, Vol.19. No.2.

Nur, M. (2018). Penerapan Model Cooperative Learning Terhadap Pembelajaran Pendidikan Agama Islam Dalam Pembentukan Perilaku Belajar Siswa Madrasah Tsanawiyah Al Ikhlas Mowewe (Doctoral dissertation, IAIN Kendari). 
Rambe, R. N. K. (2018). Penerapan strategi index card match untuk meningkatkan hasil belajar siswa pada mata pelajaran bahasa indonesia. Jurnal tarbiyah, 25(1).

Rusman. (2013). Model-Model Pembelajaran : Mengembangkan Profesinalisme Guru. Jakarta: PT Rajagrafindo Persada.

Suyadi. (2013). Strategi Pembelajaran Pendidikan Karakter. Bandung: PT Remaja Rosdakarya.

Suyanto, \& Jihad, A. (2013). Menjadi Guru Profesional : Strategi Meningkatkan Kualifikasi dan Kualitas Guru di Era Global. Jakarta: Erlangga.

Trianto. (2009). Mendesain Model Pembelajaran Inovatif-Progresif. Jakarta: Kencana Prenada Media Group.

Warsono, \& Hariyanto. (2012). Pembelajaran Aktif : Teori dan Assesmen. Bandung: PT Remaja Rosdakarya.

Zulfa, L. N. (2018). Penerapan metode cooperative learning teknik jigsaw dalam pembelajaran SKI pada kelas VIII di MTs N Karangawen Demak. Jurnal Pendidikan Agama Islam Universitas Wahid Hasyim, Vol. 6. No.1.

\section{Copyright holder :}

(C) Diah Novita Fardani (2021)

First publication right :

Journal of Contemporary Islamic Education

This article is licensed under:

CC-BY-SA 